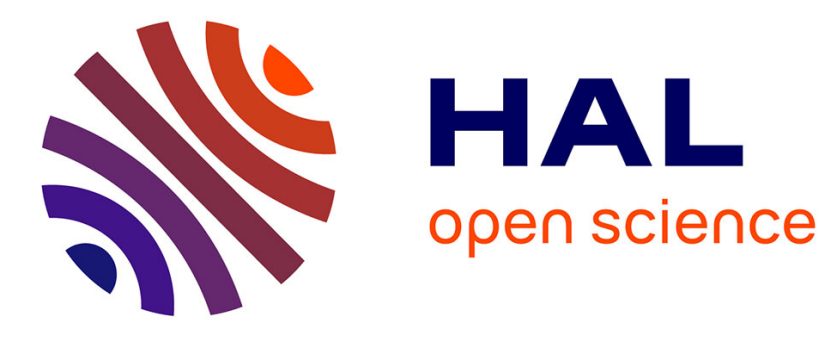

\title{
Power management in multi-microgrid system based on energy routers
}

Minh-Cong Pham, Reza Reza Razi, Quoc-Tuan Tran, Seddik Bacha, Ahmad Hably, Hossein Iman-Eini

\section{- To cite this version:}

Minh-Cong Pham, Reza Reza Razi, Quoc-Tuan Tran, Seddik Bacha, Ahmad Hably, et al.. Power management in multi-microgrid system based on energy routers. ICIT 2020 - IEEE International Conference on Industrial Technology, Feb 2020, Buenos Aires, Argentina. 10.1109/ICIT45562.2020.9067200 . hal-02398824

\section{HAL Id: hal-02398824 \\ https://hal.science/hal-02398824}

Submitted on 8 Dec 2019

HAL is a multi-disciplinary open access archive for the deposit and dissemination of scientific research documents, whether they are published or not. The documents may come from teaching and research institutions in France or abroad, or from public or private research centers.
L'archive ouverte pluridisciplinaire HAL, est destinée au dépôt et à la diffusion de documents scientifiques de niveau recherche, publiés ou non, émanant des établissements d'enseignement et de recherche français ou étrangers, des laboratoires publics ou privés. 


\title{
Power management in multi-microgrid system based on energy routers
}

\author{
Minh-Cong Pham ${ }^{1,2}$, Reza Razi ${ }^{1,4}$, Quoc-Tuan Tran², Seddik Bacha ${ }^{1}$, Ahmad Hably ${ }^{1,3}$, Hossein Iman-Eini ${ }^{4}$ \\ Univ. Grenoble Alpes , CNRS, Grenoble INP, G2Elab, Grenoble, France ${ }^{1}$ \\ CEA/INES, 50 Avenue du Lac Léman, Le Bourget-du-Lac, France ${ }^{2}$ \\ GIPSA-lab, 11 Rue des Mathématiques, Saint-Martin-d'Hères, France ${ }^{3}$ \\ School of Electrical and Computer Engineering, College of Engineering, University of Tehran, Iran ${ }^{4}$
}

\begin{abstract}
This paper proposes a peer-to-peer interaction between microgrids based on energy router to handle network congestions and other local microgrid issues in multi-microgrid system. First, an overview of energy routers in the vision of Energy Internet is addressed. Energy routers with Back-toBack converter technology is considered in this paper due to its appropriate requirement. Next, a master/slave approach for load sharing and synchronization with energy router in multimicrogrid system is investigated. Finally, a strategy for frequency coordination between microgrids is presented. In fact, in case of frequency violation, microgrids in islanded multimicrogrid system can be supported by other microgrids through an energy router interface. A simulation model is built in MATLAB/Simulink environment to evaluate the efficiency of the proposed method.
\end{abstract}

Keywords-back-to-back converter, energy router, frequency coordination, multi-microgrid, voltage source converter.

\section{INTRODUCTION}

One aspect of smart cities' development is the deployment of microgrids (MGs). They are progressively installed at the distribution level, for example the MGs capacity exceeds 1.8 GW in 2018 in the U.S [1], [2]. A group of interconnected MGs forms a multi-microgrid (MMG) system which has become a trendy research topic recently [3]-[7]. In a MMG system, it is mostly presumed that the power dispatch of MGs must pass through the power network. However, in this paper, MGs in MMG system are able to interact directly with each other. In fact, the adjacent MGs can trade energy directly, which is the key motivation for the development of the MMG system and smart grids.

In term of connection between MGs, in literature, there are two types of interconnection. In the first type, the MGs can be connected with each other's via the AC line with the use of a breaker [8], [9]. With an appropriate synchronization algorithm, this type of connection has a low investment cost. However, the main drawback of this method is the difficulty of power management between MGs. In the second type, a common DC line can be used as the interface between physical MGs [10]. In this way, each MG can be controlled dependently, which leads to flexible voltages and frequencies in the MMG system. Therefore, in this paper, the connection between MGs is enhanced by a DC line.

On the other hand, Energy Internet (EI) is a concept that has been regarded as a new evolution stage of the smart grid. EI aims to increase the energy transmission efficiency and optimize the energy dispatching in time and space. In [11], the EI is defined as an Internet-type network, consisting of all the grid elements, which closely cooperate with others by sharing both energy and information. Agents or components of this network comprise different prosumers and consumers that have the capability to carry out decisions by themselves.
MGs, distributed energy resources (DERs), smart grids, private or governmental energy networks, and any community of prosumers and consumers can be a part of this massive network as agents. In this new system, energy routers (ERs) play a key role [12]. ER is an active technological element in smart grids. ERs dynamically adjust the energy distribution in transmission and distribution networks by rerouting energy flows. In other words, ERs take on two major tasks, dynamic adjustments of energy flows and realtime communications between power devices [12]. In this paper, the methodology for controlling in MMG system through ERs technology is investigated.

The paper is organized as follows. First, an over view of ERs is described in Section II. Next, in Section III, the control of ERs is presented. Section IV indicates the simulation results and concluding remarks are presented in Section V.

\section{ENERGY ROUTERS: AN OVERVIEW}

\section{A. Functions of Energy Routers}

ERs functions can be divided into two main categories: User level and Grid level [12]. In User level, ERs connect directly to the customers and they can act as a central controller in MGs. The main task of ERs in this level is to provide all the energy services for their customers. Thus, the ERs need to enhance the plug-and-play feature of the costumers and communication with customers for providing the services. On the other hand, in the Grid level, each ER is represented for one MG. They are interfaces between the MG and other entities in the grid network such as other MGs or main grid. The objectives of ERs in this level is to manage the operation of the MGs and optimize the energy usage. ERs are able to connect or disconnect from the grid to protect the MGs system. In addition, with a smart energy management system, ERs communicate with each other for exchanging the energy to minimize the operation cost and maximize the income. For instance, by collecting the data from other ERs, MGs can negotiate and buy the surplus energy from other MGs instead of the main grid.

\section{B. Requirements of Energy Routers Architecture}

The ER is a technological integration of power electronics, communications and automations. Therefore, its design requirements include the following aspects [12], [13].

Power electronics are fundamental components in the ERs to perform automatic energy distribution and management. Therefore, all the power electronic elements must be able to operate fast and stable to guarantee the correct enforcement of the commands issued by the intelligent management module. In addition, the ERs must have an intelligence module to deal with the information about energy management from the grid system. This module utilizes the information collected through the communication module and determines the 


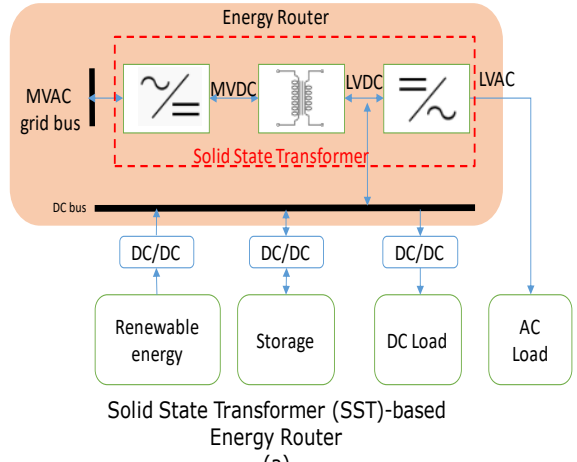

(a)

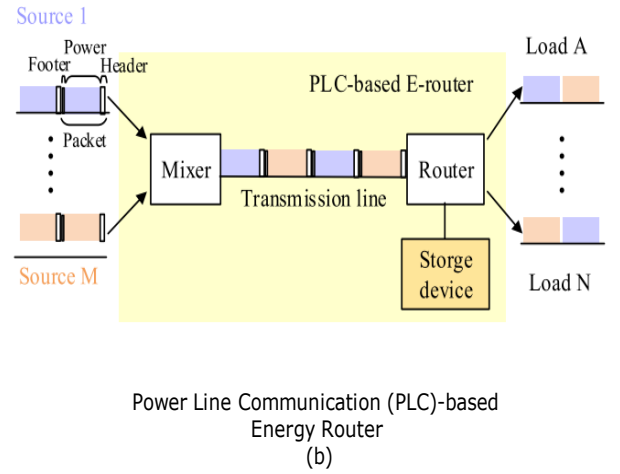

(b)

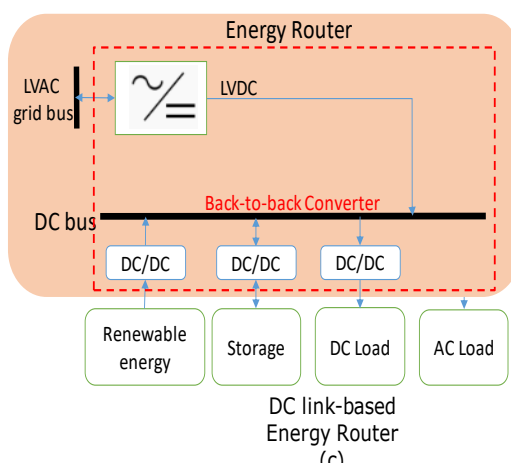

(c)

Fig. 1. Different types of the ERs (a) SST-based ERs, (b) PLC-based ERs, (c) DC link-based ERs.

control changes to be made in the grid through the ER cooperation. Plug-and-play ability, which is an important requirement feature in smart grid concept, requires the ERs a common standard interface with both energy exchange and communication functions. More particularly, they are expected to quickly analyze different classes of electrical characteristics, distinguish the load, energy storage and power generation equipment. Furthermore, the automatic access or disconnection of energy sources have to follow the user's request. Therefore, ERs architecture have to ensure this plugand-play feature. Finally, the communications between ERs must satisfy three requirements: transmission latency, communication reliability and information security.

\section{Topologies of Energy Routers}

In the literature, there are three types of ERs: Solid State Transformer (SST)-based ER, DC-link-based ER and Power Line Communication (PLC)-based ER [14].

Fig. 1 (a) presents an ER based on SST. The SST with three stage structure has the features of relatively simple control, high functionality and high reliability. Firstly, the high-voltage $\mathrm{AC} / \mathrm{DC}$ stage rectifies high-voltage alternating current (HVAC) into medium-voltage direct current (MVDC), which can be used to connect DC grids. Then, the middle $\mathrm{DC} / \mathrm{DC}$ stage adopts dual active bridge topology to transform the MVDC to a regulated low-voltage direct current (LVDC), which is used to facilitate the DC bus or connect DERs. The employment of high-frequency transformer is a benefit to attain electrical isolating and voltage converting. Finally, $\mathrm{DC} / \mathrm{AC}$ inverter generates an AC output voltage, which can be used to connect AC grids or loads. Thus, the SST-based ER can present multiple plug-and-play interfaces for access to users. Each interface may connect multiple energy networks or devices, as long as the total power does not exceed the capacity limits of the connected interface. The above SSTbased ERs are appropriate for transmission systems with high voltage and power level.

On the other hand, Fig. 1 (b) presents the PLC-based ERs. The ERs based on PLC are able to transmit energy and information through the same transmission line, which has the benefits of simple wiring and reducing device volume and cost. Nevertheless, the PLC technology performs power transmission and data communication at the same time, which is difficult to implement the time-division and multi-path transmission of power flows.

Finally, DC-link-based ERs shown in Fig. 1 (c) are useful for distribution systems which have a low voltage and power level. In the literature, DC-link-based ERs are witnessed to have a high degree of reuse and integration compared to the SST-based ERs [14]. In this architecture, through power electronic converters and information communication technology, all the components in MMG system are connected to a DC common bus, which acts as an intermediate link of the energy forwarding. The proposed DC-link can provide energy balance among multiple renewable energy sources and loads. In addition, the strategies for energy management and control can be executed directly in the controller of the converter.

This paper considers an application of ERs for a low voltage MMG system, so Back-to-Back (BTB) converterbased ERs are the best candidate. The core in ER structure is a Voltage Source Converter (VSC). The details of the selected topology is shown in Fig. 2 and will be discussed in Section III.

\section{CONTROL OF ENERGY ROUTERS}

\section{A. Control Strategy for Energy Routers}

\section{1) Peer-to-peer energy exchange}

In this paper, instead of energy trading through the main grid, MGs are able to transfer the energy directly between each other through ERs. The control strategy for ERs in MMG system is based on master/slave strategy.

The rules to choose the master converter are [15]:

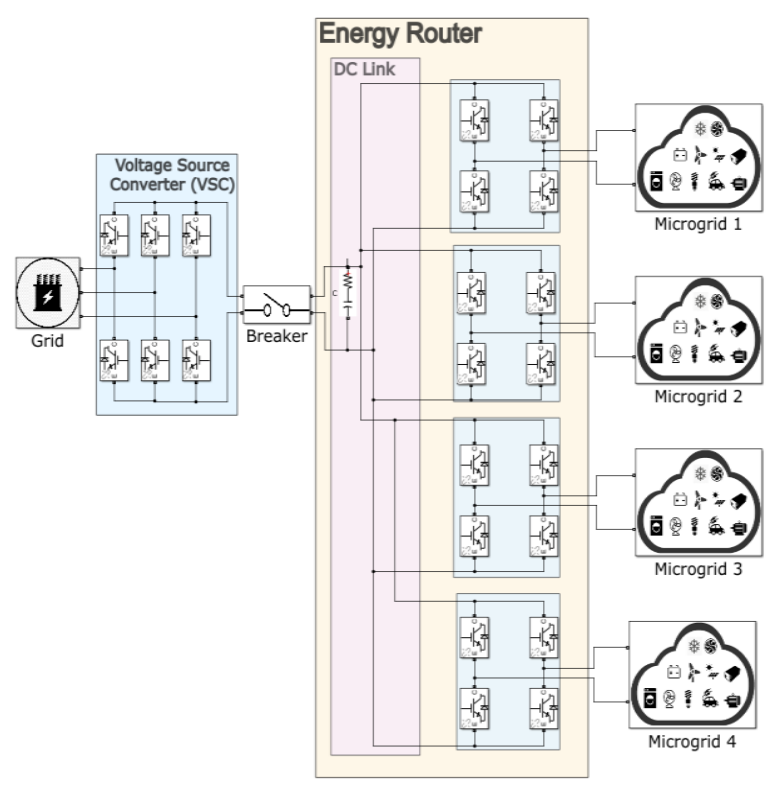

Fig. 2. The chosen topology of the ER. 
- When MMG system is connected to the main grid, VSC related to the main grid is regarded as the master converter and other VSCs are the slave converters;

- When MMG system is disconnected from the main grid, the master converter shall be the VSC in connection with the MG supplying energy to other MGs, while the other VSCs received energy shall be the slave converter. In case there are more than one MG that supply the energy, the MG with highest surplus energy is the master or the system can be run in multi-master strategy. In this paper, the first approach is selected.

With the master VSC, its outer-loop controller works as DC voltage controller to keep the DC-link voltage constant. In fact, when the converter dispatches the power, the DC bus voltage must be stable to maintain the energy balance in the system. In contrast, the other VSCs work in slave mode. Their out-loop controllers work as the active/reactive power controllers, with the purpose being to manage their power.

TABLE I. CONTROL PATTERNS FOR VSCS UNDER DIFFERENT

\begin{tabular}{ccc} 
& \multicolumn{3}{c}{ SCENARIOS } \\
\hline Control Pattern & Inner-loop & Outer-loop \\
& Controller & Controller \\
\hline Pattern 1 (master mode) & Rectifier & DC voltage control \\
Pattern 2 & Rectifier & P/Q control \\
Pattern 3 & Inverter & P/Q control \\
\hline
\end{tabular}

As defined in Table I, VSCs have three control patterns according to the operational condition of their inner and outerloop controllers. The different operational modes of the MGs are figured out by choosing appropriate control patterns for the VSCs, which will also determine the roles of the VSCs (master or slave) in the process of power flow. The master converter works in control pattern 1 and the slave converters can be chosen to work in either pattern 2 or pattern 3 , according to the role it plays in the process of power flow.

\section{2) Frequency coordination}

The frequency control of the MMG system can be improved by the ERs [16]. A summarized MMG system is shown in Fig. 3 (a), where an ER is used for interconnecting two adjacent MGs. It is assumed that converter 1 is responsible for the regulation of the DC-link voltage whereas converter 2 is used for regulating the frequencies of two adjacent MGs. The detailed frequency control of converter 2 is shown in Fig. 3 (b), which includes the current control and the multi-frequency control. The real power reference $\left(P_{B T B}\right)$ is given by the outer multi-frequency controller, as Equation (1):

$$
P_{B T B}=k_{p f}\left(f_{n 1}-f_{n 2}\right)+k_{i f} \int\left(f_{n 1}-f_{n 2}\right) d t
$$

where $f_{n 1}$ and $f_{n 2}$ are the normalized frequencies of MGs 1 and 2 , respectively; $k_{p f}$ and $k_{i f}$ are the proportional and integral gains of Proportional Integral (PI) controller in the multi-frequency controller, respectively.

The frequency of MGs is normalized to achieve the unique value of frequency deviation. Equation (2) shows the normalized frequency of $\mathrm{MG}_{\mathrm{i}}$.

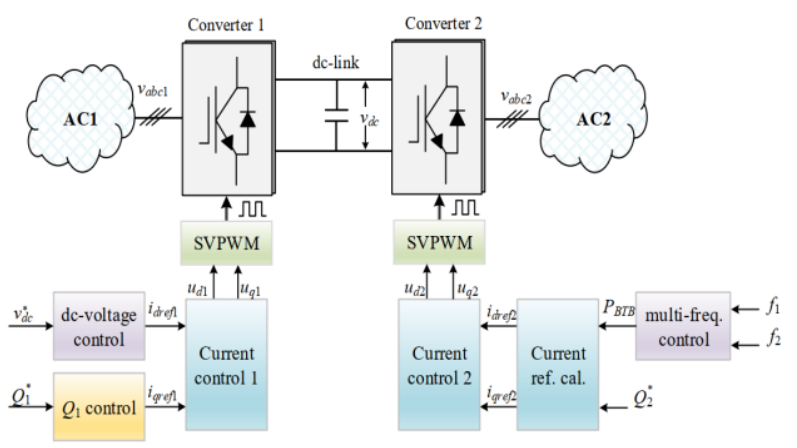

(a)

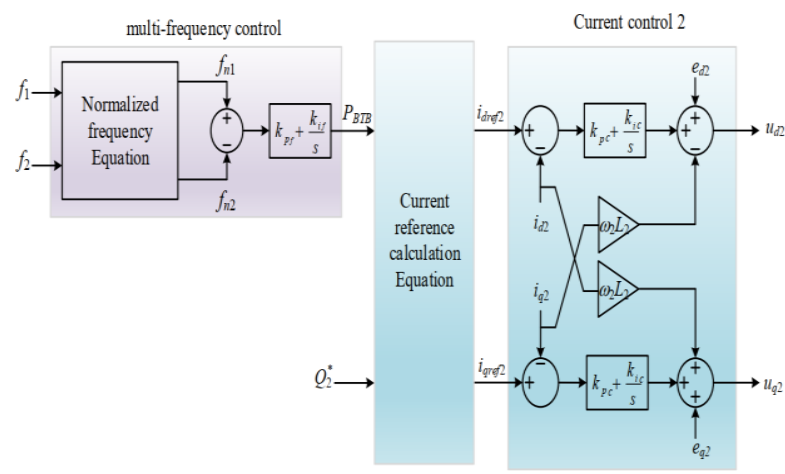

(b)

Fig. 3. (a) Frequency control in MMG system using ER and (b) its details [16].

$$
f_{n i}=\left\{\begin{array}{l}
\frac{\left(f_{i}-f_{i, \text { rated }}\right)}{\left(f_{i, \text { max }}-f_{\text {,rated }}\right)},\left(f_{i}>f_{i, \text { rated }}\right) \\
\frac{\left(f_{i}-f_{i, \text { rated }}\right)}{\left.f_{i, \text { rated }}-f_{i, \text { inin }}\right)},\left(f_{i, \text { rated }}>f_{i}\right)
\end{array}\right.
$$

where, $f_{i}$ represents the measured frequency of $\mathrm{MG}_{\mathrm{i}} ; f_{i, \text { rated }}$ is the rated frequency of $\mathrm{MG}_{\mathrm{i}} ; f_{i, \max }$ and $f_{i, \min }$ are the maximum and minimum frequency limitations, respectively.

\section{B. Dual loop controller for VSC}

The controller structure of the voltage source converters (VSCs) is shown in Fig 4. The dual-loop controllers consist of two loops: (1) the inner-loop controller, also known as the current feedback loop; (2) the outer-loop controller, which can be either a DC voltage controller or an active/reactive power controller, depending on the control objective of each VSC [15].

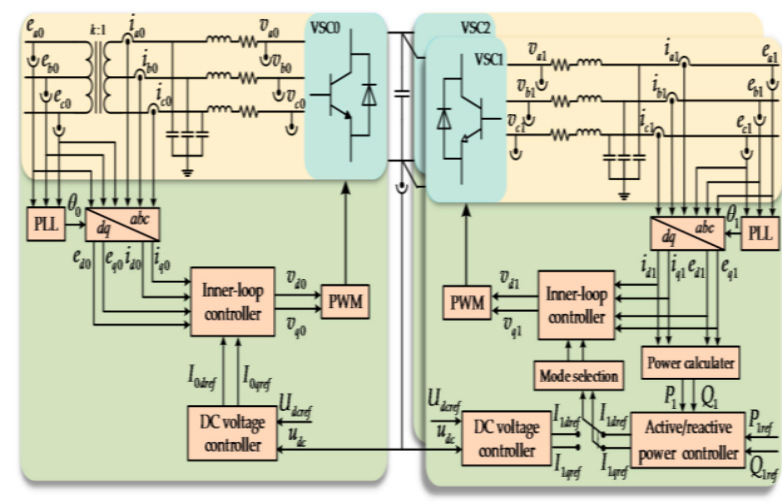

Fig. 4. Control schematic of the Voltage Source Converters (VSCs) [15]. 


\section{1) Inner loop controller}

The voltage control equations of the $\mathrm{VSC}_{\mathrm{i}}$ inner-loop controller in rectifier mode can be written as:

$$
\begin{aligned}
& v_{d i}=-\left(K_{P i}+\frac{K_{I i}}{S}\right)\left(i_{\text {idref }}-i_{d i}\right)+\omega_{i} L_{\Sigma i_{q i}}+e_{d i} \\
& v_{q i}=-\left(K_{P i}+\frac{K_{I i}}{S}\right)\left(i_{\text {iqref }}-i_{q i}\right)-\omega_{i} L_{\Sigma i_{d i}}+e_{q i}
\end{aligned}
$$

where $K_{P i}$ and $K_{I i}$ are the proportional and integral regulation gain in the inner loop, respectively. Similarly, the voltage equations of $\mathrm{VSC}_{\mathrm{i}}$ working in the inverter mode can be written as:

$$
\begin{aligned}
& v_{d i}=\left(K_{P i}+\frac{K_{I i}}{S}\right)\left(i_{\text {idref }}-i_{d i}\right)-\omega_{i} L_{\Sigma i_{q i}}+e_{d i} \\
& v_{q i}=\left(K_{P i}+\frac{K_{I i}}{S}\right)\left(i_{\text {iqref }}-i_{q i}\right)+\omega_{i} L_{\Sigma i_{d i}}+e_{q i}
\end{aligned}
$$

\section{2) Outer-loop controller}

The outer-loop is used to generate the inner-loop current reference signal and input to the inner loop control. According to different control objectives, the outer-loop controller can be classified as active/reactive power controller or DC voltage controller.

Active/Reactive Power Controller: The active/reactive power controller is used to keep the VSC working such that its active/reactive power output on the AC side shall follow the reference command value issued by the MG controller, with zero steady-state error. Classical proportional-integral (PI) regulators are used in the outer-loop control to calculate the current commands to the inner-loop with the power deviations. $P_{i}$ and $Q_{i}$ are compared with their reference inputs $P_{\text {iref }}$ and $Q_{i r e f}$, respectively, and the result of the comparison is used by the PI controller to calculate the current command value.

DC Voltage Controller: The DC voltage controller is responsible for keeping the DC-link voltage within an adequate range around the command value issued by the $\mathrm{MG}$ controller. For $\mathrm{VSC}_{\mathrm{i}}$ controlled by the $\mathrm{DC}$ voltage controller, the active power $P_{i}$ exchanged with the AC systems is identical to the DC power $P_{d c}$ stored in $C_{d c}$.

$$
P_{d c}=\frac{1}{2} C_{d c} \frac{d u_{d c}^{2}}{d t}=\sum_{i=1,2,3} P_{i}
$$

The current command input to the d-axis of the inner-loop current controller is

$$
i_{\text {idref }}=\left(K_{P d c}+\frac{K_{I d c}}{s}\right)\left(u_{d c r e f}^{2}-u_{d c}^{2}\right)
$$

where $K_{P d c}$ and $K_{I d c}$ are the proportional and integral regulation gains, respectively. With this controller, the d-axis current command is derived.

\section{Simulation Results}

The detailed model of the MMG system (Fig. 2) is implemented in the MATLAB/Simulink environment. The model is separated into five areas by an ER. In fact, for simplicity, instead of an ER for each MG, one ER is used for all MGs. The simulated system consist of four MGs which can be connected or disconnected from the main grid. Also, $\mathrm{MG}_{1}$ and $\mathrm{MG}_{4}$ have battery energy storage systems (LithiumIon batteries).

\section{A. Synchronization}

\section{1) Disconnection from the main grid}

In the first study, the transient state of the MMG system from grid connected mode to islanded mode is considered. At first, in grid connected mode, the grid converter is in master mode and the rest of converters are in slave mode. The MMG system is supplied by the main grid. At $t=5 \mathrm{~s}$, the main grid is disconnected from MMG system via a DC switch. At this moment, among four MGs, thanks to the remaining energy in battery energy storage system (BESS), $\mathrm{MG}_{1}$ has the highest surplus energy (highest SOC), so the converter of $\mathrm{MG}_{1}$ becomes the master converter. The converter of $\mathrm{MG}_{1}$ work in DC link control mode and the others work in $\mathrm{P} / \mathrm{Q}$ control mode. As a result, $\mathrm{MG}_{1}$ is responsible for supplying its load and other MGs in the system until reaches its limitation (SOC limit). The details of the active power flows and the DC-link voltage variation are demonstrated in Fig. 5.

2) Reconnection to the main grid

In this scenario, the transient state from islanded mode to grid connected mode is considered, which is shown in Fig. 6. As discussed earlier, the ERs, i.e. BTB converters, also

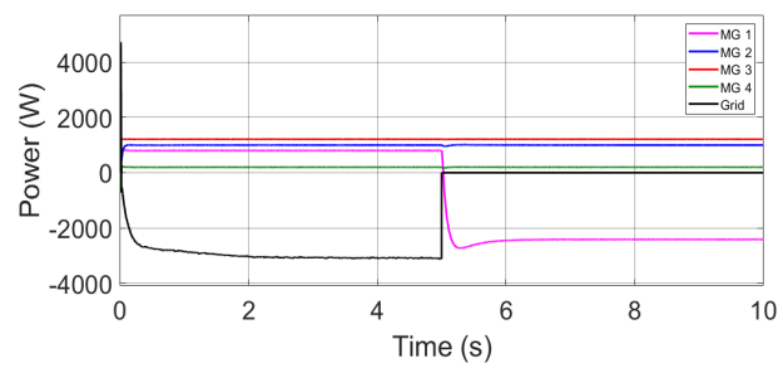

(a)

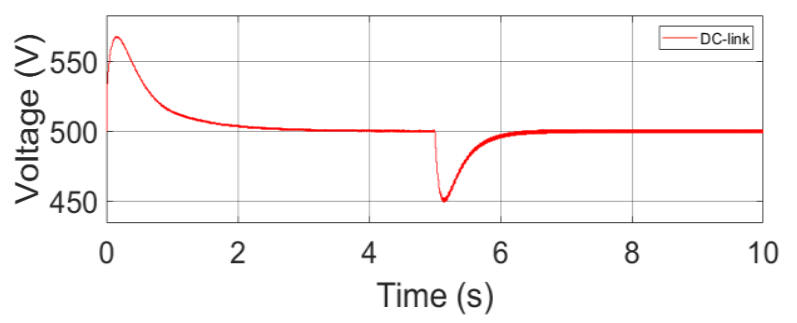

(b)

Fig. 5. Simulation results of disconnection scenario: (a) Power flow; (b) DC link voltage.

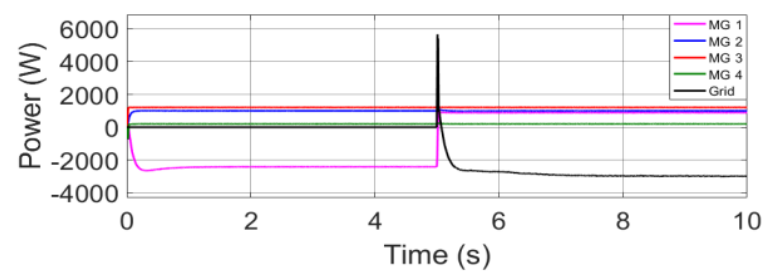

(a)

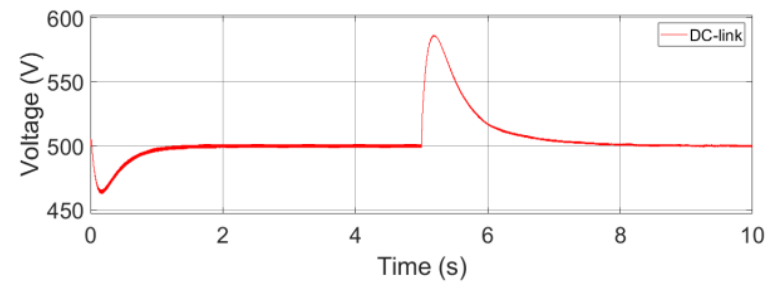

(b)

Fig. 6. Simulation results of reconnection scenario: (a) active power; (b) DC link voltage. 
provide isolation between the both sides of the DC link. Therefore, we only need to synchronize the converters in inverting mode by phase locked loop (PLL).

At first, $\mathrm{MG}_{1}$ is in master mode and the rest of inverters are in slave mode. At $\mathrm{t}=5 \mathrm{~s}$, the main grid is connected and $\mathrm{MG}_{1}$ comeback to slave mode. As shown in Fig. 6, when the system is resynchronized again, there are only slight fluctuations in the output power curves, but the fluctuation range of the DC-link voltage at the moment of power transfer is major and the stable state is restored quickly.

\section{B. Energy exchange between microgrids}

In this part, the objective of the simulations is to analyze the energy exchange in MMG system. Thus, the main grid is disconnected and the simulated MMG system is considered to work in only stand-alone mode.

\section{1) Scenario 1}

This scenario demonstrates the dynamic characteristics of the MMG system during the transient load changes. In this scenario, at $\mathrm{t}=5 \mathrm{~s}, \mathrm{MG}_{2}$ is disconnected from $\mathrm{MMG}$ system, while the power demand of $\mathrm{MG}_{4}$ increases. The operational mode of all MGs remains constant, such that $\mathrm{MG}_{1}$ serving as the master converter and other converters working as the slave converters. The variations in power flows, as well as the DClink voltage are demonstrated in Fig. 7 (a), (b) respectively.

\section{2) Scenario 2}

In this scenario, it is assumed that the MMG system has to change the master due to the energy constrain which is the state of charge (SOC) of batteries in this case.

To be in master mode in MMG system, the MG must have the highest surplus of energy. Following this strategy, all the MGs can become master, which is depended on network situation. The maximum and minimum values of SOCs of BESS in the simulation are $80 \%$ and $20 \%$, respectively. From $\mathrm{t}=0 \mathrm{~s}$ to $\mathrm{t}=5 \mathrm{~s}$, the BESS of $\mathrm{MG}_{1}$ acts as master converter to control the DC-link. So, BESS in $\mathrm{MG}_{1}$ works in discharging mode. In addition, during this period, BESS in $\mathrm{MG}_{4}$ is allowed to charge until it reaches the upper limit of SOC. On the other hand, at $\mathrm{t}=5 \mathrm{~s}$, the SOC of BESS in $\mathrm{MG}_{1}$ reaches its

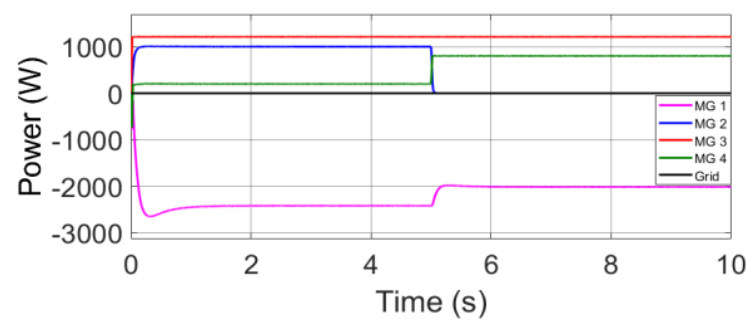

(a)

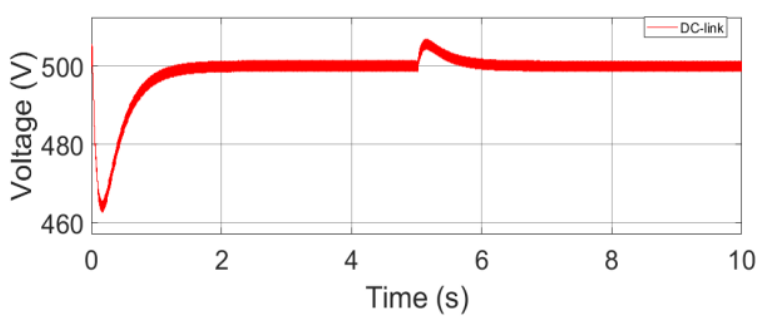

(b)

Fig. 7. Simulation results of scenario 1: (a) active power; (b) DC link voltage.

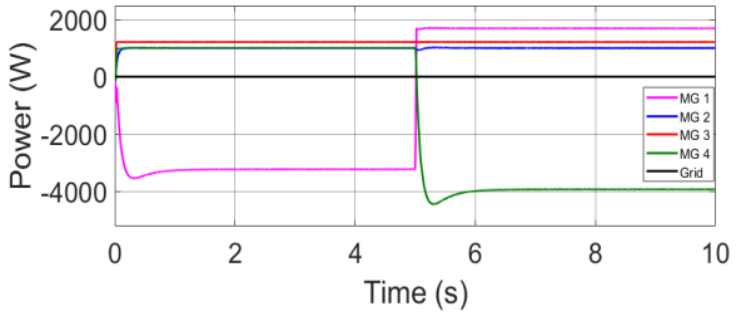

(a)

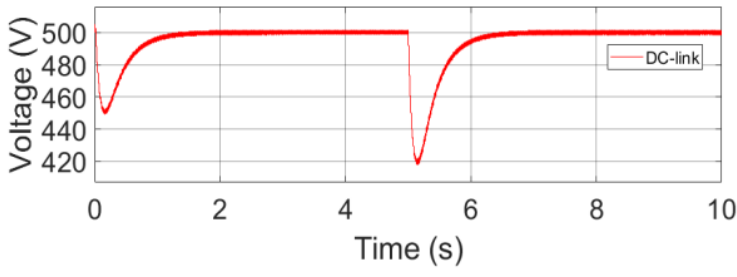

(b)
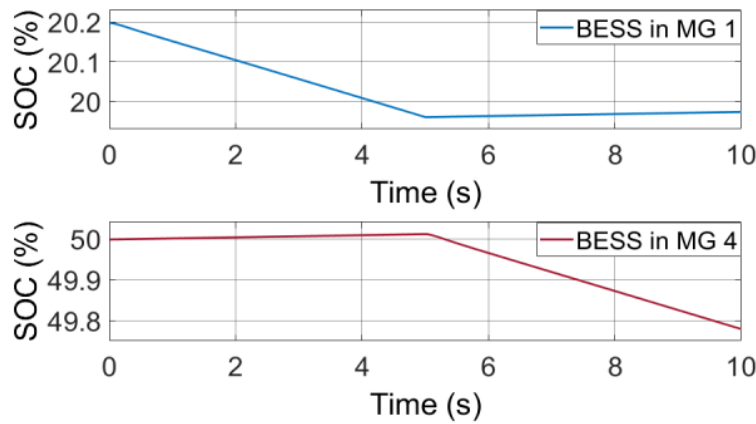

(c)

Fig. 8. Simulation results of scenario 2: (a) active power; (b) DC link voltage; (c) State of Charge (SOC) of BESS in MGs in scenario 2 .

lowest limit (20\%), so the BESS change from discharge to charge mode. In this condition, the MMG system needs a new master converter. With the SOC of BESS above $50 \%$, the converter of $\mathrm{MG}_{4}$ becomes a master converter instead of $\mathrm{MG}_{1}$. Therefore, the SOC of BESS in $\mathrm{MG}_{4}$ decreases rapidly in the last period.

Fig. 8 (a) illustrates the energy exchange in MMG system. At $\mathrm{t}=5 \mathrm{~s}$, the power curve of $\mathrm{MG}_{4}$ overtakes the one of $\mathrm{MG}_{1}$ to become the supplier for the system. There is a small fluctuation of the DC voltage when the system change the master controller (Fig. 8 (b)). The detail of SOCs of MGs is describe in Fig. 8 (c).

\section{Frequency coordination}

In this study, $\mathrm{MG}_{1}$ and $\mathrm{MG}_{4}$ are investigated for frequency coordination. They use grid-forming converters with conventional frequency droop controller. To show the effectiveness of the multi-frequency control, a comparison study between the multi-frequency control and the single frequency control is presented.

It is assumed that $\mathrm{MG}_{1}$ has a higher load condition than $\mathrm{MG}_{4}$ so the initial frequency of $\mathrm{MG}_{1}$ is lower than $\mathrm{MG}_{4}$. In $\mathrm{t}=2.5 \mathrm{~s}$ and $\mathrm{t}=3.5 \mathrm{~s}$, more loads are added into the $\mathrm{MG}_{1}$, respectively, which worsens the frequency condition in $\mathrm{MG}_{1}$. Initially, there is different frequencies in steady state. In fact, the frequency of $\mathrm{MG}_{4}$ with single frequency control remains constant because there is no disturbance in $\mathrm{MG}_{4}$. But, with the multi-frequency controller, the frequencies of both MGs 


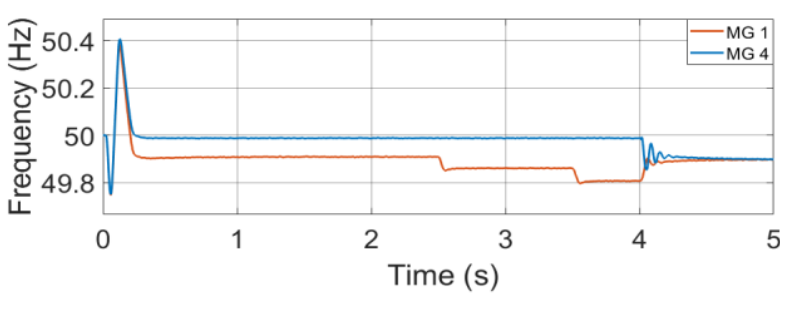

Fig. 9. Simulation results for frequency coordination scenario.

are considered in the ER. The disturbance in $\mathrm{MG}_{1}$ can be recognized by the multi-frequency control. Fig. 9 shows frequency waveforms of the MMG system using either single frequency control or the multi-frequency control. In this scenario, it is assumed that the proposed control method is only applied when the MGs reach a critical value (below 48.8 $\mathrm{Hz}$ and above $50.2 \mathrm{~Hz}$ ). Therefore, as shown in Fig. 9, at time $\mathrm{t}=3.5 \mathrm{~s}$, when $\mathrm{MG}_{1}$ drops in the frequency by $49.8 \mathrm{~Hz}$, the proposed control is activated. The power reserve in $\mathrm{MG}_{4}$ can then be shared accordingly to recover the $\mathrm{MG}_{1}$ frequency. As a result, the frequency of $\mathrm{MG}_{4}$ is deviated by the disturbance in $\mathrm{MG}_{1}$ and the frequency of $\mathrm{MG}_{1}$ has come back to the acceptable value.

\section{CONCLUSION}

In conclusion, in this paper, the interface between MGs via ERs is developed. Firstly, to cooperate between MGs, the control approaches and interconnections between them are presented. A peer-to-peer control strategy for interaction in the MMG system is selected. Next, the paper introduces the concept of ER as an interface among MGs, with its characteristics, design requirement, functionalities and topologies for implementation. DC-link-based ER technology is chosen to apply in the paper. To verify the ER application, a stand-alone MMG system with ER interface is simulated in MATLAB/SIMULINK environment. In the case of transient events such as disconnection/reconnection with the main grid, the ER is able to keep the DC-link voltage stable. In addition, MGs are allowed to exchange the energy directly among them via the ER interface. The energy constraints of the MGs such as the SOC is also investigated. A methodology for frequency coordination through ERs is also introduced in this paper. This approach is implemented when MGs are not able to maintain their standard frequency. With that, MGs can be supported by other MGs, which not only improves the reliability of MGs, but also reduces the cost of ancillary services.

\section{ACKNOWLEDGMENT}

This work has been supported by the m2M-GRID project of the joint programming initiative ERA-Net Smart Grids Plus.

\section{REFERENCES}

[1] R. H. Lasseter, "Smart Distribution: Coupled Microgrids," Proc. IEEE, vol. 99, no. 6, pp. 1074-1082, 2011

[2] M. Munsell, "US Microgrid Capacity Will Exceed 1.8GW by 2018le." [Online]. Available: https://www.greentechmedia.com/articles/read/us-microgrid-capacitywill-exceed-1-8-gw-by-2018\#gs.kagzqb.

[3] N. Hatziargyriou, MICROGRIDS ARCHITECTURES AND CONTROL, 1st ed. West Sussex, United Kingdom: John Wiley and Sons Ltd, 2014.

[4] H. Zou, S. Mao, Y. Wang, F. Zhang, X. Chen, and L. Cheng, "A Survey of Energy Management in Interconnected Multi-Microgrids," IEEE Access, vol. 7, pp. 72158-72169, 2019.

[5] V. H. Bui, A. Hussain, and H. M. Kim, "A multiagent-based hierarchical energy management strategy for multi-microgrids considering adjustable power and demand response," IEEE Trans. Smart Grid, vol. 9, no. 2, pp. 1323-1333, 2018.

[6] H. Farzin, M. Fotuhi-Firuzabad, and M. Moeini-Aghtaie, "Enhancing Power System Resilience Through Hierarchical Outage Management in Multi-Microgrids," IEEE Trans. Smart Grid, vol. 7, no. 6, pp. 28692879, 2016.

[7] J. Zeng, J. Peng, C. Zhang, W. Zhang, and S. Zhou, "Research on islanding partition algorithm for the multi-microgrids," J. Eng., vol. 2019, no. 16, pp. 3345-3348, 2019.

[8] W. Liu, W. Gu, Y. Xu, Y. Wang, and K. Zhang, "General distributed secondary control for multi-microgrids with both PQ-controlled and droop-controlled distributed generators," IET Gener. Transm. Distrib., vol. 11 , no. 3, pp. 707-718, 2016.

[9] C. Yuen, A. Oudalov, and A. Timbus, "The provision of frequency control reserves from multiple microgrids," IEEE Trans. Ind. Electron., vol. 58, no. 1, pp. 173-183, 2011.

[10] A. Kargarian and M. Rahmani, "Multi-microgrid energy systems operation incorporating distribution-interline power flow controller," Electr. Power Syst. Res., vol. 129, pp. 208-216, 2015.

[11] H. Pourbabak, T. Chen, and W. Su, Centralized, decentralized, and distributed control for Energy Internet. Elsevier Ltd, 2018.

[12] Y. Xu, J. Zhang, W. Wang, A. Juneja, and S. Bhattacharya, "Energy router: Architectures and functionalities toward energy internet," 2011 IEEE Int. Conf. Smart Grid Commun. SmartGridComm 2011, pp. 3136, 2011.

[13] R. Wu, B. Wang, Y. Zou, B. Fan, L. Li, and Z. Zhu, "Energy router interface model based on bidirectional flow control for intelligent park," Proc. IECON 2017 - 43rd Annu. Conf. IEEE Ind. Electron. Soc., vol. 2017-Janua, pp. 7771-7776, 2017.

[14] H. Guo, F. Wang, J. Luo, and L. Zhang, "Review of energy routers applied for the energy internet integrating renewable energy," 2016 IEEE 8th Int. Power Electron. Motion Control Conf. IPEMC-ECCE Asia 2016, no. 51577113, pp. 1997-2003, 2016.

[15] Y. Liu, Y. Fang, and J. Li, "Interconnecting microgrids via the energy router with smart energy management," Energies, vol. 10, no. 9, 2017.

[16] H. J. Yoo, T. T. Nguyen, and H. M. Kim, "Multi-frequency control in a stand-alone multi-microgrid system using a back-to-back converter," Energies, vol. 10, no. 6, 2017. 